\title{
GELENEKSEL ANLATMA FORMLARINDAN ÇAĞDAŞ ROMANA AKTARIMLAR YA DA İHSAN OKTAY ANAR'IN ROMANLARINDA POST-MODERN ANLATICI PROFILLERI* ${ }^{*}$
}

\section{Osman GÜNDÜZ**}

\begin{abstract}
$\ddot{O} \mathbf{z}$
Kurmaca metinlerde önemli bir yer tutan anlatıcıyı, kurmaca dünyayı biz okurlara nakleden bir varlık olarak tanımlamak mümkün. Sözlü dönemde bu anlatıcı etiyle kemiğiyle insandır. Meddah - anlatıcı adını verdiğimiz bu anlatıcının başarı ölçüsü ve kalıcıllğı, büyük ölçüde sahne performansı ve yetenekleri ile sinırlıdır. Geleneksel anlatı ürünlerinde uzun süre varlığını sürdüren bu anlatıcılar, ilk dönem romanlarımızın da temel figürlerini oluşturmaktadır. Yazarın kimliğiyle örtüşen bu anlatıcının, zamanla yerini yazar dışında bir kurmaca varlık olan farklı anlatıcılara bıraktığı; geçen yüzyılın ortalarında ise birtakım yeni anlatım teknikleriyle eski gücünü büyük ölçüde yitirdiği bilinen bir durumdur. Ne ki bu anlatıcı profili, günümüzde, romanı bir anlatı, kurguyu ise bir oyun hâline getiren çağdaş romancıların eserlerinde önemli bir değişime uğramış; ilk modellerini anımsatan ancak biraz parodileştirilmiş yeni kimliğiyle varlığını sürdürmektedir. Bu çalışmada, günümüz post-modern romancılarından İhsan Oktay Anar'ın sözünü ettiğimiz geleneksel anlatı ürünlerine özgü nakilcilerinden ve meddah-anlatıcilarından söz edilecektir.
\end{abstract}

Anahtar Sözcükler: Anlatıcı, meddah anlatıcılar, nakilciler, post-modern roman, İhsan Oktay Anar.

\section{TRANSFERS FROM THE CONVENTIONAL EXPRESSION FORMS TO CONTEMPORARY NOVEL OR POST-MODERN NARRATOR PROFILES IN İHSAN OKTAY ANAR'S NOVELS}

\begin{abstract}
It is possible to define the narrator, an important item for fiction texts, as the body that conveys the fictional world to us, the reader. During the verbal period, the narrator is literally human. Success criterion and persistency for this narrator, called meddah (public storyteller), are majorly limited by stage performance and skills. These narrators that had long-lasting influences on conventional narrating products are also the basic figures of our prime noveling period. It is apparent that once overlapping with the author; these narrators gradually left their places to different fictional narrators and lost their previous importance and became obsolete with some new narration or expression techniques. However this narrator profile underwent a substantial change today in contemporary novelists' works who change novel into narration and fiction into a play; became something resembles parody and maintains its existence with this new identity that reminds its essential models. In this notice, I will mention narrators and meddahs -public
\end{abstract}

\footnotetext{
* Bu makale, 03.02.2016 tarihinde düzenlenen IX. Euroopen Conference on Social and Behavioral Science ParisFrance February 03.02.2016 adlı sempozyumda sunulan bildirinin geliştirilmiş ve yeniden düzenlenmiş hâlidir.

** Prof. Dr.; Atatürk Üniversitesi Kâzım Karabekir Eğitim Fakültesi Türkçe Eğitimi Bölümü, ogunduz25@gmail.com.
} 
storytellers- intrinsic to contemporary post-modern novelist İhsan Oktay Anar's conventional narration products.

Keywords: Storyteller, meddah narrators, narrators, post-modern novel, İhsan Oktay Anar.

\section{Geleneksel Anlatma Formu}

İhsan Oktay Anar, hemen tüm romanlarında okurun karşısına destan, masal, halk öyküsü, efsane... gibi geleneksel anlatma formlarından beslenen bir üslup ile çıkar. Post-modern anlatı yazarlarının sadece biçimsel olarak yararlandıkları bu anlatma tarzının belirgin özelliği, birtakım söz kalıplarının ve figürlerin yardımıyla metin oluşturmaktır. Sözlü kültürden gelen ve zaman içinde biçimlenen söz kalıpları, anlatıların bellekte saklanmasını ve yeniden kullanımını kolaylaştırdığı gibi toplumun kültürel birikimini ve bilgece yanını da yansıtırlar. Nitekim deyim, atasözü, tekerleme gibi kalıplaşmış formlar ve geleneksel anlatıcılar metne zenginlik katmakta, aynı zamanda birbirine eklenmiş farklı öyküleri kullanan yazara da geniş olanaklar sunmaktadır. Doğal olarak bu tarz anlatım biçiminin okurun ilgisini canlı tuttuğunu da gözden uzak tutmayalım.

Anar'ın romanlarının karakteristiğini oluşturan geleneksel anlatma formu ile ilgili unsurlar, alt kültüre mensup birtakım nakilcilerden ve meddah anlatıcılardan, bu anlatıcılara özgü dil ve söyleyiş tarzına, klişe yer ve kişi betimlemelerinden gizemli sayılara ve objelere, ayna ve rüya gibi motiflere kadar çeşitlilik gösterir. Ancak Anar, tüm bu geleneksel anlatma formlarında ve figürlerinde birtakım değişiklikler yaparak hem okuru bilinenlere karşı yabancılaştırır, hem tarihsel olana yeni yorumlar getirerek bilinenler hakkında okuru kuşkuya düşürür, hem de çağdaş romancılar tarafından küçümsenen bu anlatım tarzına yeni açılımlar ve bakış açıları kazandırarak farklı ama özgün bir anlatım modeli üretir. İşte romanları farklı kılan da bu özelliğidir.

Söz konusu bu anlatım biçimi ya da yaygın adıyla üslup, aynı zamanda yazarın geçmişe özgü bu çeşitten olaylara bakış açısını da sezdirmektedir. Nitekim romanlarda sıkça görülen 'Raviyân-ı ahbar ve nakilan-ı âsâr, Yafes Çelebi'nin bu akılalmaz tasarıları Zencefil Çelebi adında bir zata anlattığını rivayet ederler ki..' (Kitabü'l Hiyel, 1996, s. 20), 'Kurşunlu Mahzen Kâtibi Hamamcı Musa Efendi'nin görkemli eseri Tezakirü'l-Mücrimin'de anlatıldı̆̆ına göre.' (Amat, 2005, s. 11), 'Sözüne güvenilir bir alim olan Buhur mütevellisi Kılbaz Yakup Dede Hazretleri de bu olayın doğru olduğuna dair, Menakıbü'l Mebain adlı eserinde yemin üzerine yemin etmiştir.' (Amat, 2005, s. 104), 'Kuşşubaşı Halifesi Kuyruklu Rıza Çelebi, Kitabü’l İber 
Geleneksel Anlatma Formlarından Cağdas Romana Aktarımlar, Ya Da İhsan Oktay Anar'ın Romanlarında PostModern Anlatıcı Profilleri

TAED $57 * 1783$

başlıklı manzum eserinde anlattıkları doğruysa..' (Amat, 2005, s. 89), 'Kuşçubaşı Halifesi Kuyruklu Rıza Çelebi, Kitabü'l İber adlı eserinde... Masraf Kâtibi Kuzguni Halim Efendi ise, Silsiletü'l Havadis adlı eserinde (...) beyan etmiştir.' (Amat, 2005, s. 49), 'Ayasofyalı deliler taifesi arasında kendisinin Sultan Mahmud olduğunu iddia eden Ahırkapılı mecnun Zincirli Mahmud'un güruhundan biri olup onun vakanüvisliğini yapan Divane Salim Efendi'den, Süleymaniye Timarhanesi güllabicibaşısı Demirtokat Haydar Bey'in naklettiğine göre..' (Kitabü'l Hiyel, 1996, s. 27), 'Râviyân-ı ahbar ve nakilân-ı âsâr kâh hayretü minnet, kâh nefretü ibretle şunlarl rivayet ve hikâyet ederlerdi...' (Kitabü'l Hiyel, 1996, s. 9) gibi anlatım formlarıyla oluşturulmuş ifadeler ve söz kalıpları oldukça fazladır. Geleneksel metinlerden taklit yoluyla alınmış ya da onlara öykünerek oluşturulmuş bu söz kalıplarının anlamı şudur: Zaman zaman yazar anlatıcı, kimi zaman yazarın kendisi, romanın karakterlerinden birinin ya da meddah anlatıcının kimliğine bürünerek sözlü kültürün dilsel zenginliğini naklederken, anlatılanların göreceliğini, tarihin ise bakış açısına göre farklı yorumlanabileceğini ve bu konuda tek bir doğrudan söz edilemeyeceğini de anlatmaktadır.

\subsection{Meddah Anlatıcılar}

Anar'ın klasik anlatı türlerine getirdiği yeniliklerin başında daha çok sözlü anlatı ürünlerinde görülen ve klasik anlatıcılara alternatif olarak geliştirdiği meddah-anlatıcılar gelir. Çağdaş romancılar tarafından küçümsenen bu anlatım tarzına yeni açılımlar ve bakış açıları kazandıran Anar, aynı zamanda bu anlatım tarzlarından farklı anlatıcı modelleri de üretir. Yer yer yazarın kimliğiyle örtüşen bu anlatıcıların öne çıkan vasıfları, lâubali bir üslupla olayları anlatmaları ve yorumlamalarıdır. Farklı bir söyleyişle bu anlatıcılar, okurla senli benli konuşan ve onunla sohbet eden bir meddahı anımsatırlar. Söz gelişi Efrasiyab’ın Hikâyeleri'ndeki Bidaz'ın Laneti adlı öykü, Anadolu'daki öykü-masal anlatma geleneği hakkında bilgi vererek başlar. İlkin Anadolu'da hüküm süren masal anlatma geleneğinden ve masalın bir çeşit terbiye unsuru olduğundan söz edildikten sonra konu kahvelerde anlatılan define öykülerine ve oradan da define arayıcılığına taşınır ve sonunda öykünün konusunu oluşturan adını andığım define öyküsüne getirilir:

Anadolu köylerinde gecelerin, özellikle çocuklar için çok uzun, çok zevkli ve biraz 'ürpertici' geçmesinin sebeplerinden biri de, dedelerin ve ninelerin anlattığl şu cinli perili masallardl. Sinilerde yemek yendikten sonra torun tosun, doğruca ninenin yanına gelir, o sırada kahvesini içen kadından masal anlatmasını istirham ederlerdi. 
Rahmetli kocasıly didişmeleri, konu komşuyla yaptığ dedikodular, çekiştirmeler ve çektiği zllgitlar sonucu, kelimelerin insan üzerindeki güçlü etkisi konusunda adeta mütehassıs kesilmiş olan kadın da zavallıların ricasını kırmaz, bir gece öncekinden çok daha korkunç bir hikâye anlatırdı. Böylece çoluk çocuk, sabi sübyan hep birlikte, ana baba sözüne kulak asmayıp dereye yıkanmaya giden kırk yaramaz veledin şöhretli dev İsfendiyar tarafindan bir bir enselenerek tandırda kebap edildikten sonra nasıl mideye indirildiğini ses soluk etmeden, bet beniz atmış bir hâlde dinlerlerdi... (Efrasiyab’ın Hikâyeleri, 1998, s. 39-43).

Ne var ki bu tür romanlarda bir alt kültürün diliyle ya da jargonuyla yazmak sadece Anar’a özgü değildir. Söz gelişi Orhan Kemal, Çukurova köylülerinin ve kasaba insanlarının; Kemal Tahir, Çorum, Çankırı köylülerinin küfürlü konuşmalarını, âdetlerini ve yaşam biçimlerini abartılı olarak verirler. Bu hususta biz okurlar için zengin bir malzeme sunan Anar'ın romanlarından birkaç örnek vermekle yetineceğim:

Çileden çıkan dede, hınçtan alt dudă̆ını ısırarak, bir hamlede kaldırdı̆̆ı asasını utanmaz tüccarın beynine tam indiriyordu ki, talih eseri rüya kesildi ve edepsiz, paçayı kıl payı kurtardı (Efrasiyab'ın Hikayeleri, 1998, s. 90).

Nezaket ve korku gereği elbette yüzüne karşı Nafile Kalfa denilen kadının gerçek lakabı, söylenmesi burada pek münasip olmayacak kadar ayıp sayılırdı. Fakat edep ve terbiye dışı lakap ona hitap edilirken asla telaffuz edilmezdi. Bu kadın kırklı yaşlarda bir kız kurusuydu (Efrasiyab’ın Hikayeleri, 1998, s. 150).

..bu ihtiyarın ăgzı son derece pisti! Ona buna kantarlı, sunturlu, okkalı küfürler savurmayı huy edindiği için tam iki kez mehterandan kovulup ekmeğinden olma tehlikesi atlatınca Kalın Musa, 'Bir daha küfür edersem ecdadımı cümle âlem kerksin!' diye yemin etmişti. Ama defter-i kebirinde öyle sövgüler vardı ki, dirhemini yiyen it kudururdu (Suskunlar, 2007, s. 17).

\subsection{Nakilciler}

İhsan Oktay Anar, iç öykülerini ya da çerçeve öyküyü oluşturan olayları kurmaca dünyanın bilinen anlatıcıları aracılığıyla nakletmek yerine ikinci elden veren nakilcilere anlattırır. Meddah anlatıcı konumundaki yazar anlatıcı ise tüm bu anlatılanları toparlayıp düzenlemekle görevlidir. Abartılı ön adlar ve unvanlar taşıyan bu nakilciler, Anar'ın romanlarında önemli bir işleve sahiptirler. 
Geleneksel Anlatma Formlarından Çăgdaș Romana Aktarımlar, Ya Da İhsan Oktay Anar'ın Romanlarında PostModern Anlatıcı Profilleri TAED $57 * 1785$

Ancak Anar, nakilcilerin kimlikleri konusunda geleneksel anlatma formundan ayrilır. İlk bakışta öykücükleri ciddi kaynaklara dayandırıyor ve bilimsel bir hava veriyor gibi görünse de aslında nakilcilerin adlarından ve abartılı kimliklerinden pek güvenilmez, yarı meczup, cahil kişiler olduklarını sezdirmektedir. Bir eleştirmenin yerinde saptamasıyla Anar, yabancılaştırma tekniğini kullanarak bir yandan ciddi görülen pek çok bilginin göreceli, anlatılan metnin ise kurmaca olduğunu düşündürürken, bir yandan da tarihi ironik bir üslupla yorumlayarak ve fantastik unsurlarla zenginleştirerek yeniden kurgulamaktadır. (Yalçın-Çelik, 2005, s. 157). Ayrıca bu bol lakaplı ilginç adlı anlatıcılar, metni eğlenceli bir oyun hâline getirdikleri gibi, romanı tek anlatıcıya dayalı metinlerin tekdüzeliğinden de kurtarırlar.

Romanlarda nakilci olarak kullanılan 'Delisakal İzzet Efendi dünürü Kız Halil Çelebi, Tabanıyassızade Tiryaki Beşir Bey, Kadıkaryeli Rıza Paşa’nın afyoncubaşısı Duhani İmdat Efendi, Să̆ garipler devecisi Dörtboynuz Halil Efendi, Cenabet Haydar Paşa'nın yeğeni Lalezar Fülfül Çelebi, Ahırkapılı mecnun Zincirli Mahmud, Tatavla delilerinden Divane Salim Efendi, Fitilikısa Cuma Paşazade Zil Tevfik Efendi, Tokatçı Kevakib Efendi, Davulcuzade Cümbüş̧ Efendi, Leblebici Kıl Hüsrev Bey, Havai Efraim Bey, Tatavla Delilerinin Sonuncusu Divane Asım Efendi, Delisakal İzzet Efendi Dünürü Kız Halil Çelebi, Eliuzun Kâmil Paşa dünürü Altın Bey, Çeşm-i Yek Boncuk Çelebi, Galatalı hekim Avram Efendi, Buzağızade Maymun Ilham Efendi, Çapraz Gülcemal Efendi...' gibi daha pek çok adı burada sıralamak mümkün. Bu nakilciler dışında Vakanüvis Şaşı İkram Efendinin Kevaşifü'l Melanet ve'l Habaset (Amat, 2005, s. 29), Zindan kâtibi Çapraz Recep Dede Hazretlerinin El Müsvette fi Usulü'l Livata (Amat, 2005, s. 35), Müjdecibaşı Kedigöz Abidin Dede Hazretlerinin Kitabü’l İber (Amat, 2005, s. 187), Kurşunlu Mahzen Kâtibi Musa Efendinin Tezakirü'l Mücrimin (Amat, 2005, s. 11), Kuşçubaşı Halifesi Kuyruklu Rıza Çelebinin Kitabü'l İber (Amat, 2005, s. 29), Masraf Kâtibi Kuzguni Halim Efendinin Silsiletü'l Havadis (Amat, 2005, s. 49), Selam Ağası Kekez İsmail Dede Hazretlerinin Akaidü'r Rezail (Amat, 2005, s. 185), Yedekçibaş1 Maymuni İlyas Baba Hazretlerinin El Beyan fi Makasid'ül Lûtiyan (Amat, 2005, s. 185) Ruznamçe Kisedarı Ölügözlü Cuma Bey’in Kamusü'l Desais (Amat, 13), Buhur Mütevellisi Kılbaz Yakup Dede Hazretlerinin Menakıbü'l Mebain (Amat, 2005, s. 209)... adlı eserleriyle romanlara kaynaklık edenlerin eserlerinin çağrıştırdıklarından ve ilginç ön adlarından güvenilmez kişiler, kaynaklar oldukları sezdirilir. Bu nakilcilerin üslupları ve kişilikleri ile ilgili iki örnek vereceğim: 
...Zalimler ve muhterisler, âlimler ve vakanüvisler, halimler ve muhlisler, doğru ya da yanlış, şu menkıbeleri salnamelerde rivayet ve meyhanelerde hikâyet etmişlerdir: Zürafa zadegânnndan, Emir Buhari şeyhi Beşir Efendizade Kumru Çelebi, Calud'un Mağripli olduğunu garaib defterinde zikretmesine rağmen, peşkir ağası Ani Efendi ile Dolmabağçe reisületibbası Kirami Efendi'nin, onun Filisti olduğunu beyan ettikleri rivayet-i mevsukadandır. Esirhane kethudası Kâmi Efendi'nin köşkündeki natırlardan Çeşm-i Badem Ceylan Hatun ise, esirhane gulamlar defterinde onun adının Câlud el-Filistî diye geçtiğini kerrelerce ilan eylemiş, bu da onun halis Filisti olduğunun delili sayılmıştır. Ceylan Hatun'un torunlarından Siyahî Sabit Bey'den nakledildiğine göre, Calud esir pazarında mezata çıkarılır çıkarılmaz, maslahatı, gerek eni, gerek boyuyla müşteri taifesini hayretü dehşet içinde biraktı̆̆ından alıcı yılmış, böylece değerinin kat be kat altında satılmıştı ki, kethüda Kâmi Efendi'nin deftere düştüğ̈̈ kayıt bunu doğrulamıștır (Kitabü’l Hiyel, 1996, s. 67).

Benzer anlatıcılarla ve aynı üslupla Anar'ın öteki romanlarında da karşılaşmak mümkün:

Kuş̧̧ubaşı Halifesi Kuyruklu Rıza Çelebi'nin Ruznamçe Kisedarı Ölügözlü Cuma Bey'den naklettikleri doğruysa, Hamamcı Musa Efendi, Tezakirü'l Mücrimin başlıklı eserini işte bu kahvehanenin müdavimleri arasinda geçen konuşmalardan ilham alarak yazmıştı. Her ne kadar başkaları itiraz etseler de, Galatalı hekim Avram Efendi ve yarenlerince 'Deli Marangoz' diye anllan Nuh Usta ve grandi direğine kara sancak çekilmiş Amat adlı kalyon, bu eserin ikinci babinda bütün tafsilattyla anlatılmaktaydı ki, ne kadarının doğru olduğunu yalnızca Allah bilir (Amat, 2005, s. 225-226).

Yazar metne gerçeklik süsü vermek için farklı yollar dener. Bazen olayları bir vakanüvis üslubuyla ve dönemin bilimsel anlayışına uygun olarak farklı kaynaktan/nakilciden yararlanarak nakleder. Böylece anlatımının gerçekliğini güçlendirmeye çalışır. Önce yazar anlatıcı aracılığıyla dönemin tarihsel kanıtlarını kullanır. Şu örneğe bir bakalım:

Tarihçiler ve vakanüvisler, Galata Mevlevihanesi'nin karşısındaki evde, o gece cereyan eden olaylar hakkinda ihtilafa düşü̈şlerdir. Her şeyden önce, Calud'un şaşırmasına neyin sebep olduğuna dair rivayetler muhteliftir. Karaaygır Bayram Paşazade Sünnetçi Imdat Efendi'nin naklettiğine göre Calud, eski efendisinin avucundaki taşı kara yakut sandiğı için hayret etmiştir. Oysa Kürd Recep Efendi onun, Yafes Çelebi'nin hayranlık ve pişmanlı dolu tavrını gördüğ̈̈ için apıştı̆ıııı 
Geleneksel Anlatma Formlarından Cağdas Romana Aktarımlar, Ya Da İhsan Oktay Anar'ın Romanlarında Post\begin{tabular}{lr} 
Modern Anlat1c1 Profilleri & TAED $57 * 1787$ \\
\hline
\end{tabular}

beyan etmektedir. Durum ne olursa olsun, raviyan-l ahbar ve nakilan-l asar Calud'un olağanüstü bir olayın cereyan ettiğini sezdiği konusunda hemfikirdir (Kitabü'l Hiyel, 1996, s. 74).

Anar, romanının kurmaca olduğunu sık sık anımsatır. Özellikle öyküleri ya da metin halkalarını naklederken nakilcilerin farklı rivayetlerine gönderme yapar. Söz gelişi anlatıcı roman kişileriyle ilgili bilgi aktaracak. Bu konuda bir ön bilgi verdikten sonra sözü nakilciye birakır:

Yafes nam bu çelebi Tophanevî idi, bedesten esnafları onun Saraçhaneli olduğunu, mahlasinin da Seyfi olduğunu nice sonra tellallarla ilân ve defterlerde beyan etmiş̧lerse de sonuçta taşralı değil İstanbulî idi. Kazasker'deki demirciler çarşısında, Sultan Abdülaziz devri saltanatlarında bile onun adını hatırlayan ustalar çıkmıştı. Fakat hatırladıkları, çehrelerine öfkeden kan hücum etmesinden belli olur, o anda kendilerine yüz kuruş bile verilse meşum saydıkları o ismi ağızlarına almazlardl. Bu öfkenin sebeplerine dair rivayetler muhteliftir. Kllınç dövme sanatında asrının piri kabul edilen Hacıkadınlı merhum Deli Bekir'den ikinci kalfası Kul Rıza'nın naklettiğine göre Yafes Çelebi, daha ter bıylkll, ayva tüylü, paluze tenli bir delikanll iken kllnç dövme sanatına heves etmiş ve bunun için demirciler çarşısında Zekeriya Ustanın elini öptükten sonra çıraklığa kabul edilmişti (Kitabü’l Hiyel, 1996, s. 9-10).

Kimi zaman da tersini yapar. Nakilcileri kullanırken son sözü yazar anlatıcıya söyletir: Meselâ Calud, devridaim makinesi için bedestenden satın aldığı 'Passakal' icadı olan bir mekanik hesap makinesi üzerinde çalışmakta ve onu geliştirerek iktidarını güçlendirecek güçlü bir makineye dönüştürmeyi amaçlamaktadır. Olayların nakli şöyle gerçekleşir:

...Ancak Kadanacı Abidin Çavuş, Calud'un bu çılgınca tasarısında ciddi olup olmadı̆̆ında kolay kolay hüküm verilemeyeceğini, çünkü bilindiği gibi onun insanlarla dalga geçmeyi pek sevdiğini, menkıbeyi rivayet eden Davulcuzade Cümbüş Efendi'nin ise fazlaslyla saf bir zat olduğunu beyan etmiştir. Ne var ki Deli Rıza Efendi, Papacı Karl adında bir kâfirin dört işlem yapabilen bir hesap makinesi tasarladığıın işiten Calud'un ziyadesiyle etkilendiğini rivayet etmişstir ki, menkibeler doğru olsun ya da olmasın, sonuç olarak o dönemde bu hiyelkâr adamın kafasının bir hayli karışılk olduğuna bir delil teşkil ederler. Dokuzblyık Basri Bey ise arzularını sürekli kamçılayıp büyüten Calud'un böylece, kafasında firtınalar estiği hâlde kendisini kaftan kafa uzanan bir umman içinde /tek başına hissedince 
çaresizce bazı yardımcılar aramaya başladı̆̆ını Kul Reşid Çavuş'tan nakletmiştir (Kitabü'l Hiyel, 1996, s. 85-86).

Meddah anlatıcı, geleneksel anlatma formlarını ve meddah ağzını kullanmakla birlikte, yerine göre, kendine özgü bir vokabüler de kullanır.

Geçmişte ve gelecekte, yerlerde ve göklerde, meydana gelmiş ya da henüz vaki olmamış olayların ve görüngülerin tekmilini; bu esrarengiz âlemde cereyan eden her şeyin gidişatına yön ve anlam veren tabiat kanunlarınl; kâinatın iç yüzünü; gök gürültü̈sü(nü), şimşek ve firtınaların esrarını; seyyareler(in) ve kuyruklu yıldızların yörüngelerini; öterek birbirlerine durmadan Süleyman ve Saba Melikesi'ne ait hazinelerin yerini söyleyen kuşların konuştuğu dili ve grameri; elmas, yakut, zümrüt veya değerli ve değersiz bütün kristallerin muammasinl; Hazreti Yusuf'un zürriyetine eziyet eden Firavun Kavmi zamanindan kalma akll almaz papirüs rulolarındaki kördüğümlerin çözümünü; kurşunu uygun miktarda kükürtle karıştırarak altın elde etmenin püf noktasını; Doğu'nun tapınaklarında yüzlerce silahl muhafiz tarafindan korunan batıni kitaplardaki bit yeniklerini;.... (Efrasiyab'in Hikâyeleri, 1998, s. 106).

Anar, bu tür anlatma formunun gereği olarak zaman zaman sözü yazar anlatıcıdan alır ve roman yazarına bırakır. Söz gelişi Efrasiyab'ın Hikâyeleri'nin Dünya Tarihi adlı öyküsünde Anadolu tüccarlarının aç gözlülüklerinden, iki yüzlülüklerinden, inanç sömürücülüğünden ve bu yolda yaptıkları düzenbazlıklarından uzun uzadıya söz ettikten sonra sözlerini kimliğini sezdiren şu cümlelerle tamamlar:

...Aslında tüccar taifesi hakkında diğer şeyler de yazllsa, buna ne kalem ne de kâğıt dayanırdı. Ancak bu taifeden, durumun farkinda olan bazılarl, yatarlar, kalkarlar, kendilerini bu kadar insafla tasvir eden muharrire sabah akşam dua ederlerdi (Efrasiyab'in Hikâyeleri, 1998, s. 87).

Kimi zaman 'Daha taşranın taşra olduğu zamanlarda, yani bundan otuz kirk yıl kadar önce küçük şehir ve kasabalarda, doğrusu ahali adabı muaşerete daha fazla düşündü..' (Efrasiyab’n Hikâyeleri, 1998, s. 141) gibi cümlelerle anlatıcıyı aşarak doğrudan kendi düşüncelerini yansıtırken; kimi zaman da meddah anlatıcı kimliğini öne çıkarır: 
Geleneksel Anlatma Formlarından Çăgdaș Romana Aktarımlar, Ya Da İhsan Oktay Anar'ın Romanlarında Post\begin{tabular}{ll} 
Modern Anlatıc Profilleri & TAED $57 * 1789$ \\
\hline
\end{tabular}

Vaktiyle Erzurum'un Derman Mahallesi'nde, dadaşlardan Selami Tuz adında, dinibütün, namazında niyazında gayet sofu bir şahsın iki oğlu vardı. Bunlardan, isminin zikredilmesi şimdilik pek münasip olmayacak olan büyük oğul, sabahtan akşama kadar ibadet eder, sofuluk hususunda muhterem pederiyle âdeta yarışırdı (Efrasiyab’in Hikâyeleri, 1998, s. 101).

Sonuç olarak buraya kadar verdiğim çeşitli örnek alıntılardan da anlaşılacağı üzere Anar, mimetik romancıların aşırı duyarlılık gösterdikleri bilinen anlatıcılardan farklı olarak, sözlü gelenekten gelen meddah anlatıcilara ve nakilci konumundaki anlatıcalara yer vermekle hem bilinen anlatıcı algısını değiştirmiş, hem de mimetik romancıların küçümseyerek baktıkları bu anlatıcılara işlevsellik kazandırmıştır.

\section{Kaynaklar}

Anar, İ. O. (1995) Puslu kıtalar atlası (31. bs. 2007). İstanbul: İletişim Yayınları.

Anar, İ. O. (1996). Kitab-ül hiyel (15. bs. 2007). İstanbul: İletişim Yayınları.

Anar, İ. O. (1998). Efrasiyab'ın hikâyeleri (16.bs. 2006). İstanbul: İletişim Yayınları.

Anar, İ. O. (2005). Amat (3. bs. 2006). İstanbul: İletişim Yayınları.

Anar, İ. O. (2007). Suskunlar. İstanbul: İletişim Yayınları.

Gündüz, O. (2012). Ihsan Oktay Anar'ın kurgu dünyast, ya da Anar'in kurgu evreninde postmodern bir gezinti. Ankara: Grafiker Yay.

Yalçı-Çelik, S. Dilek (2005), Eski zaman mucitlerinin inanılmaz öyküleri kitabü'l hiyel: hiyel mi yoksa hayal mi?. Yeni Tarihselcilik Kuramı ve Türk Edebiyatında Post-modern Tarih Romanları, Ankara: Akçă̆ Yayınları, 150-183. 